\section{Commentary: Biomechanical remodeling of the pulmonary autograft after the Ross procedure}

\author{
Gediminas Gaidulis, $\mathrm{PhD}$, and \\ Muralidhar Padala, $\mathrm{PhD}$
}

The Ross procedure is a safe and effective aortic valve replacement option for younger patients with aortic valve disease. Being a living valve substitute, with tissue architecture, hemocompatibility, and dynamics close to the native aortic valve, the theoretical benefits of such an option are several, especially in patients with a longer life expectancy. Although its use has been limited to few specialized centers across the world, the outcomes of Ross procedure have been superior to most other options. Age-corrected survival rates after Ross procedure have been equivalent to the general population, which demonstrates the superiority of this approach over other available techniques. ${ }^{1}$

Despite the anatomical and structural similarities between the pulmonary autograft and the native aortic valve, the pulmonary autograft is in a lower-pressure environment until the time of surgery. Once transpositioned into the aortic position, it experiences a greater luminal pressure, which can elevate wall stresses in each cardiac cycle. Anatomically, the pulmonary autograft is part of the main pulmonary artery, which is a relatively long, straight conduit, whereas in the aortic position, it assumes the curvature of the ascending aorta. Furthermore, in the aortic position, the coronary ostia implanted into the autograft alter the fluid mechanics on the ventricular surface of the pulmonary valve leaflets. This non-native hemodynamics and

\footnotetext{
From the Structural Heart Research and Innovation Laboratory, Carlyle Fraser Heart Center, Emory University Hospital Midtown; and Division of Cardiothoracic Surgery, Emory University, Atlanta, Ga.

Disclosures: G.G. has no conflicts to disclose. M.P. reports a significant stock ownership in Nyra Medical Inc, and receiving consulting fees from Heart Repair Technologies Inc and Boston Scientific in the past 12 months.

The Journal policy requires editors and reviewers to disclose conflicts of interest and to decline handling or reviewing manuscripts for which they may have a conflict of interest. The editors and reviewers of this article have no conflicts of interest.

Received for publication Oct 27, 2021; revisions received Oct 27, 2021; accepted for publication Oct 27, 2021; available ahead of print Oct 29, 2021.

Address for reprints: Muralidhar Padala, $\mathrm{PhD}$, Cardiothoracic Research Laboratories, 380B Northyards Blvd, Atlanta, GA 30313 (E-mail: spadala@emory.edu).

J Thorac Cardiovasc Surg 2022;164:1739-40

$0022-5223 / \$ 36.00$

Copyright (c) 2021 by The American Association for Thoracic Surgery

https://doi.org/10.1016/j.jtcvs.2021.10.043
}

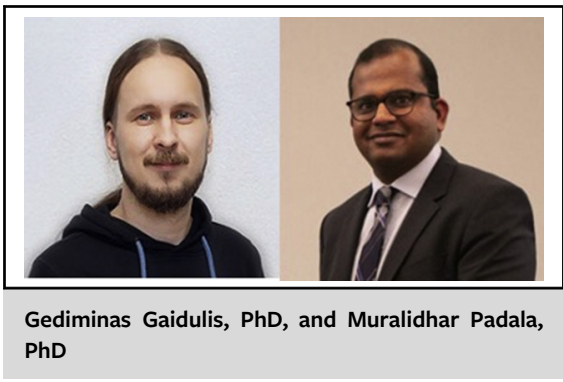

CENTRAL MESSAGE

Can the pulmonary autograft

thrive in the systemic

environment?

mechanics can be transduced by the pulmonary autograft, leading to its potential remodeling and in some cases failure from exaggerated autograft dilatation.

This research question has been studied by several, and it continues in this manuscript ${ }^{2}$ from Dr Elaine Tseng's group at University of California San Francisco, in collaboration with the clinical Ross program of Dr Ismail Elhahamsy at Montreal Heart Institute and Mt Sinai Hospital. ${ }^{3-5}$ The authors sought to examine autograft wall stresses after the Ross procedure using patient-specific material properties of the tissue. Several novel aspects make it a commendable effort toward a better understanding of autograft remodeling and dilatation. First, the authors created and used realistic image-based computational models, and it is advantageous over the studies with idealized models that are not patient-specific. In addition, patient-specific material properties were determined for each case separately. Since determination of such material properties is timeconsuming for every study, the authors also examined the influence of patient-specific versus averaged material properties and found no significant differences in the magnitude and location of wall stresses. Computational models were validated by overlaying the computed geometries and magnetic resonance imaging at diastole. A good agreement between simulation results and medical images was found.

A thing worth mentioning is the large volume of this study, with data sets of 16 patients used to create computational models. Usually, similar studies use 1 or 2 models to test the hypothesis, since computational models are solving for mathematical equations and they do not have the same measurement errors as experimental models have. In contrast, a large-volume study allows a strong validation of the simulation workflow and enables a wider range stress 
analysis, a quantity that cannot be directly measured in vivo and can only be determined numerically.

While the study is interesting and provides important results for further autograft remodeling research, there are some limitations that need to be highlighted. First, the pulmonary autograft geometries were obtained from magnetic resonance imaging in patients performed at 1 year after the Ross procedure. The autograft may have already remodeled by this time, and the wall stresses are indicative of remodeling and may not provide a causative link between the biomechanical state and graft remodeling. Second, the aortic valve was not included in the computational models, since the authors were focused mainly on wall stresses and had not investigated velocity distribution and flow characteristics. While reconstruction of the valve geometry and its coupling with the aorta is a complicated task, adding the aortic valve would have an impact on blood flow, likely to be significant. This in turn might also influence stress distribution along the aortic wall, thus leading to more realistic simulation results. In addition, patient-specific blood pressures were not accounted for. This is a little bit disappointing, especially since all the other aspects of the simulation protocol were patient-specific, including the material properties, rarely seen in computational studies of such a large volume.

\section{References}

1. Romeo JLR, Papageorgiou G, da Costa FFD, Sievers HH, Bogers AJJC, ElHamamsy I, et al. Long-term clinical and echocardiographic outcomes in young and middle-aged adults undergoing the Ross procedure. JAMA Cardiol. 2021;6: 539-48.

2. Xuan Y, Alonso E, Emmott A, Wang Z, Kumar S, Mongeon F-P, et al. Wall stresses of early remodeled pulmonary autografts. J Thorac Cardiovasc Surg. 2022;164: 1728-38.e2.

3. Matthews PB, Jhun CS, Yaung S, Azadani AN, Guccione JM, Ge L, et al. Finite element modeling of the pulmonary autograft at systemic pressure before remodeling. J Heart Valve Dis. 2011;20:45-52.

4. Vanderveken E, Vastmans J, Claus P, Verbeken E, Fehervary H, Van Hoof L, et al. Mechano-biological adaptation of the pulmonary artery exposed to systemic conditions. Sci Rep. 2020;10:2724.

5. Nappi F, Nenna A, Lemmo F, Chello M, Chachques JC, Acar C, et al. Finite element analysis investigate pulmonary autograft root and leaflet stresses to understand late durability of Ross operation. Biomimetics (Basel). 2020;5:37.
See Article page 1728.

\section{Commentary: An opportunity for a new look at the Ross autograft}

\author{
Jeremy L. Herrmann, MD ${ }^{\mathrm{a}, \mathrm{b}}$
}

The famed Italian anatomist Antonio Valsalva is credited for discerning the relationship between eddying aortic sinus blood flow and leaflet closure in the early 1700s. ${ }^{1}$ However, Leonardo da Vinci observed this phenomenon and even developed a functional glass model of the aortic root 2

\footnotetext{
From the ${ }^{\mathrm{a}}$ Division of Thoracic and Cardiovascular Surgery, Indiana University School of Medicine; and ${ }^{\mathrm{b}}$ Riley Children's Health at Indiana University Health, Indianapolis, Ind.

Disclosures: The author declares no conflict of interest.

The Journal policy requires editors and reviewers to disclose conflicts of interest and to decline handling or reviewing manuscripts for which they may have a conflict of interest. The editors and reviewers of this article have no conflicts of interest.

Received for publication Aug 26, 2021; revisions received Aug 26, 2021; accepted for publication Aug 27, 2021; available ahead of print Sept 4, 2021

Address for reprints: Jeremy L. Herrmann, MD, Division of Thoracic and Cardiovascular Surgery, Indiana University School of Medicine, Riley Children's Health at Indiana University Health, 545 Barnhill Dr, Emerson 215, Indianapolis, IN 46202 (E-mail: jlherrma@iupui.edu).

J Thorac Cardiovasc Surg 2022;164:1740-1

$0022-5223 / \$ 36.00$

Copyright (c) 2021 by The American Association for Thoracic Surgery

https://doi.org/10.1016/j.jtcvs.2021.08.065
}

Check for updates

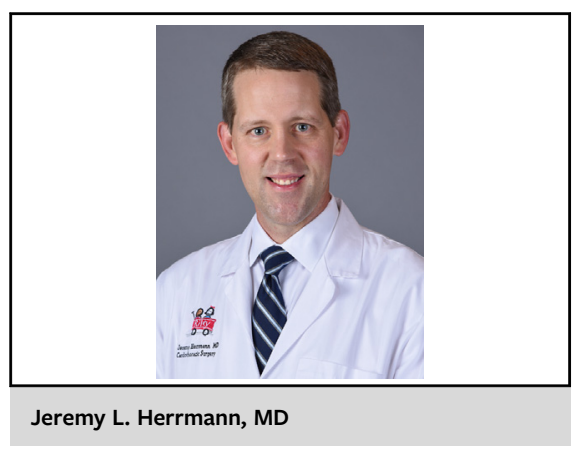

CENTRAL MESSAGE

This proof-of-concept study

provides a novel modeling tech-

nique for analyzing Ross auto-

graft wall stresses.

centuries prior. ${ }^{1,2}$ It is therefore remarkable that 500 years since Leonardo's death, we are provided with a novel technique for examining the form and function of the (neo-) aortic root. ${ }^{3}$ The present study entailed a combination of patient-specific geometry and material properties to perform finite element analysis to estimate wall stress at each component of the Ross neoaortic root. ${ }^{3}$ Aortic and 